\title{
Synergistic Effects of Forensic Medicine and Traumatology: Comparison of Clinical Diagnosis Autopsy Findings in Trauma- Related Deaths
}

\author{
Uwe Schmidt $^{1} \cdot$ Delovan Oramary $^{2} \cdot \operatorname{Konrad~Kamin}^{2} \cdot$ Claas T. Buschmann $^{3}$ • \\ Christian Kleber ${ }^{2}$
}

\begin{abstract}
Background Trauma is the third leading cause of death worldwide after cardiovascular and oncologic diseases. Predominant causes of trauma-related death (TD) are severe traumatic brain injury (sTBI), hemorrhagic shock, and multiple organ failure. An analysis of TD is required in order to review the quality of trauma care and grasp how well the entire trauma network functions, especially for the most severely injured patients. Furthermore, autopsies not only reveal hidden injuries, but also verify clinical assumed causes of death.

Material During the study period of 3 years, a total of 517 trauma patients were admitted to our supraregional University Centre of Orthopaedics and Traumatology in Dresden. 13.7\% (71/517) of the patients died after trauma, and in 25 cases $(35.2 \%)$, a forensic autopsy was instructed by the federal prosecutor. The medical records, death certificates, and autopsy reports were retrospectively evaluated and the clinical findings matched to autopsy results. Results The observed mortality rates (13.7\%) were $4.2 \%$ less than expected by the calculated RISC II probability of survival (mortality rate of $17.9 \%)$. The most frequent trauma victims were due to falls $>3 \mathrm{~m}(n=29)$ ), followed by traffic accidents $(n=28)$. The median ISS was 34 , IQR 25 , and the median New ISS (NISS) was 50, IQR 32. Locations of death were in emergency department (23.9\%), ICU (73.2\%), OR and ward (1.4\%, respectively). Clinicians classified $47.9 \%$ of deaths due to sTBI $(n=34)$, followed by $9.9 \%$ thoracic trauma and multiple organ failure $(n=7), 8.4 \%$ multiple trauma $(n=6)$, and $2.8 \%$ hypoxia and exsanguination $(n=2)$. In $18.3 \%$, cases were unspecific or other causes of death recorded on the death certificates. Evident differences with evident clinical consequences were ascertained in $4 \%(n=1)$ and marginal clinical consequences in 24\% (6/25). In 16\% (4/25), marginal differences with minor forensic consequences were revealed.

Conclusions Even in a supraregional trauma center, specialized in multiple trauma management $(4.2 \%$ survival benefit), room for improvement exists in more than a quarter of all casualties. This underlines the need for higher autopsy rates to uncover missed injuries and to understand the pathomechanism in each trauma fatality. This would also help to uncover potential insufficiencies in clinical routines with regard to diagnostics. The interdisciplinary cooperation of trauma surgeons and forensic pathologists can increase the quality of trauma patient care.
\end{abstract}

Uwe Schmidt

uwe.schmidt@tu-dresden.de

1 Institute of Legal Medicine, Medical Faculty Carl Gustav Carus, Technical University Dresden, Fetscherstrasse 74, 01307 Dresden, Germany
2 University Center of Orthopaedics and Traumatology, AG Polytrauma, University Medicine Carl Gustav Carus, Technical University, Fetscherstrasse 74, 01307 Dresden, Germany

3 Charité - Universitätsmedizin Berlin corporate member of Freie Universität Berlin, and Berlin Institute of Health, Institute of Legal Medicine and Forensic Sciences, Humboldt-Universität zu Berlin, Berlin, Germany 


\section{Introduction}

Multiple trauma is defined as a combination of different life-threatening injuries or an Injury Severity Score (ISS) of $>16$ points [1-3]. Trauma is the third leading cause of death worldwide after cardiovascular and oncologic diseases. However, trauma is one of the main causes of death in infants, adolescents, and young adults $(\leq 44$ years of age) [4]. The consequences of trauma include human and social burdens such as disability, inability to work, and the need for high-maintenance care [5]. Predominant causes of trauma-related death are severe traumatic brain injury (sTBI), hemorrhagic shock, and multiple organ failure $[6,7]$. Trunkey's trimodal temporal distribution model of traumatic death in relation to survival time was a milestone in trauma research [7, 8]. Kleber et al. [6] investigated 440 trauma deaths that occurred in Berlin in 2010 and revealed no evidence of a late peak. Their temporal analysis of traumatic death indicated a shift from the classic trimodal distribution to a new bimodal distribution. Based on deaths that occurred within $1 \mathrm{~h}$ and 24-48 $\mathrm{h}$ after trauma, two hot spots of trauma care were detected: emergency management and critical care.

During the last 30-40 years, trauma mortality has declined due to improved road safety programs and innovations in trauma management [9]. In particular, priorityguided systematic trauma management (e.g., Advanced Trauma Life Support management approach) and wholebody computed tomography (CT) have improved trauma management, resulting in better detection and treatment of life-threatening injuries [10]. Because of the routine use of CT diagnostics by the new generation of physicians dealing with trauma management, these physicians may have accumulated less experience in detecting life-threatening injuries via clinical examination, sonography, or conventional imaging. In contrast, patients who require critical care or resuscitation are not suitable for CT scanning and have a high risk of missed injuries. Therefore, analysis of traumatic deaths is needed to review the quality of trauma care in trauma centers and determine how well the whole trauma network functions, especially for the most severely injured patients. The autopsy has the potential to provide an educational tool for health care providers [11]. Performance of autopsies after traumatic deaths can improve management quality by decreasing the rate of missed injuries and thus verifies the clinically assumed cause of death [1]. Therefore, in the future, this would allow the possibility of improving trauma care pathways and providing a better chance for learning. Autopsies also play a crucial role in identifying areas in which further research or financing could improve trauma care [4].
This study was performed to examine the clinical causeof-death diagnoses and autopsy findings in level I trauma centers in an effort to improve the quality of trauma management and identify starting points for improvement.

\section{Materials and methods}

During the 3-year study period (January 1, 2014, to December 31, 2016), 517 patients who matched the criteria of the German Trauma Registry were admitted to the hospital after trauma and were either treated in the intensive care unit or died during hospitalization at the University Centre of Orthopaedics and Traumatology, University Medicine Carl Gustav Carus Dresden (level I/supraregional trauma center). Inclusion criteria for the German TraumaRegister DGU are due to trauma admissions via emergency room and observation on ICU or dying during trauma management or referral from other trauma centers within the trauma network.

The Carl Gustav Carus University Hospital is one of two certified supraregional trauma centers in the trauma network of east Saxony. This trauma network comprises two supraregional, five regional, and six local trauma centers covering an area of $17,000 \mathrm{~km}^{2}$. Of the 517 patients, 71 $(13.7 \%)$ died after trauma in our center. The federal prosecutor instructed a forensic autopsy to be performed on 25 of these patients (Group I), and from 46 of these patients, an autopsy was not instructed (Group II).

The patients' medical records, death certificates, and autopsy reports were retrospectively evaluated, and the clinical findings were compared with the autopsy results. Data were acquired from the electronic medical records and death certificates. All autopsies were mandated by the public prosecutor. The autopsy findings were taken from the section protocols. An interdisciplinary survey (forensic medicine, traumatology) was separately and independently performed in all cases. After the interdisciplinary evaluation, the authors revealed discrepancies between the clinical and autopsy results in a peer-review mode.

According to the reports by Trunkey [8] and Kleber et al. [6], survival was categorized as follows: immediate death to $60 \mathrm{~min}, 1-4 \mathrm{~h}, 4-48 \mathrm{~h}, 2-7$ days, and $>7$ days after trauma.

The discrepancies were categorized into two groups: (1) Evident discrepancies with relevant clinical and/or forensic consequences were defined as valid autopsy findings that were not described or treated in the clinical records or that were incorrectly interpreted and contributed to death. (2) Marginal discrepancies with minor clinical and/or forensic consequences were defined as autopsy findings that were not described clinically or that were incorrectly interpreted but that did not contribute to death and might not have 
influenced management. Discrepancies were further analyzed with respect to the preventability of death and categorized as not preventable, potentially preventable, and definitely preventable [12].

As the patient cohort represents the elderly population, preventable complicated polytrauma outcomes such as systemic inflammatory reaction syndrome, sepsis, and acute organ failures could be overrepresented. In our study, different scores were calculated.

In spring 2016, an updated sepsis definition (Sepsis-3) introduced a new explanation for the clinical picture of sepsis. Until then, sepsis had been understood as a "systemic inflammatory response syndrome (SIRS)" resulting from infection. For a better understanding of molecular mechanisms, the clinical appearance shifted its focus from inflammatory responses to multi-causal tissue damage resulting in organ dysfunction [13]. Sepsis should be defined as a life-threatening organ dysfunction caused by a dysregulated response to infection. For clinical assessment, organ dysfunction could be represented by an increase in the Sequential [Sepsis-related] Organ Failure Assessment (SOFA) score of two points or more, which is associated with an in-hospital mortality greater than $10 \%$ [14].

The initial, highest, and mean SOFA scores correlate well with mortality. Initial and highest scores of more than 11 or mean scores of more than 5 corresponded to mortality rates of more than $80 \%$ [15]. The mean SOFA score in our four subgroups ( $\leq 45$ years or elder; autopsy or no autopsy) ranged between 14 and 15.5 points. Similar results were found for SAPS II and APACHE II score. A significant difference was seen through the variables due to age group $</>45$, gender ( $p$ 0.006), SAPS II highest score during treatment $(p$ 0.004), and lactate upon arrival in the emergency room $(p 0.015)$.

The descriptive statistical analysis was performed via PASW 23.0 (IBM Corp., Armonk, NY, USA). Non-normally distributed data are presented as median and interquartile range, and normally distributed data are presented as mean and standard deviation. The Mann-Whitney $\mathrm{U}$ test was used for independent group comparison. A $p$ value of $<0.05$ was considered statistically significant.

\section{Results}

\section{Characteristics of all the deceased patients}

In total, $71(13.7 \%)$ of the severely injured patients died within the observation period at our center. This observed mortality rate was $4.2 \%$ lower than expected by the calculated Revised Injury Severity Classification II (RISC II) probability of survival (mortality rate of $17.9 \%$ ) [16].
Group of deceased patients comprised 43 men and 28 women with a mean age of $64 \pm 23$ years (range 1-94 years). The mean age of the women $(75.3 \pm 15.4$ years $)$ was significantly higher than that of the men $(56.3 \pm 24.2$ years $)(p=0.001)$.

\section{Trauma mechanism and injury severity}

The most frequent trauma mechanisms were falls of $>3 \mathrm{~m}$ $(n=29)$ followed by traffic accidents $(n=28)$, falls of $<3 \mathrm{~m}(n=6)$, firearm injuries $(n=2)$, stab wounds $(n=2)$, and other mechanisms $(n=4)$. The median ISS was $34, \mathrm{IQR} 25$, and the median New ISS (NISS) was 50, IQR 32.

\section{Distribution of traumatic deaths}

Most traumas ( $n=57 ; 80.3 \%$ ) occurred from the morning to the late evening (08:00-23:59). Among the traumas that occurred on weekdays, most took place on Monday $(n=14 ; 19.9 \%)$. Seventeen $(23.9 \%)$ patients died in the emergency department, 52 (73.2) died in the intensive care unit, one $(1.4 \%)$ died in the operating room, and one $(1.4 \%)$ died on the ward.

\section{Characteristics of group I}

The public prosecutor mandated autopsies to be performed on 25 patients, representing an autopsy rate of $35.2 \%$ (25/ 71) of all of the deceased patients. This group comprised 15 men with an average age of $50 \pm 28$ years (range 1-93 years) and ten women with an average age of $74 \pm 19$ years (range 26-89 years). The median ISS was 34 points, IQR 25, and the mean median New ISS (NISS) was 50 points, IQR 27.

\section{Characteristics of group II}

On 46 patients, an autopsy was not performed. This group was comprised of 28 men with an average age of $60 \pm 22$ years (range 20-86 years) and 18 women with an average age of $76 \pm 13$ years (range 46-94 years).

The median ISS was 34 points, IQR 26, and the mean median New ISS (NISS) was 50 points, IQR 32.

We examined the age-related differences in the performance of autopsies within each sex. Men who underwent autopsy were 10 years younger than men who did not ( $p=0.17)$. Among women, however, we detected no agerelated difference in the performance of autopsies $(p=0.92)($ Table 1).

The trauma mechanism influenced whether an autopsy was ordered by the federal prosecutor. Whereas $100 \%$ of pedestrians who died in traffic accidents underwent 
Table 1 Performance of autopsy according to age and sex: Men who underwent autopsy were significantly younger than women who underwent autopsy. Additionally, men who underwent autopsy were significantly younger than men who did not undergo autopsy

\begin{tabular}{lllll}
\hline Gender & Autopsy & N & Mean Age & Std. \\
\hline Female & No & 18 & 76.2 & 13.4 \\
& Yes & 10 & 73.7 & 19.1 \\
& Total & 28 & 75.3 & 15.4 \\
Male & No & 28 & 59.9 & 21.7 \\
& Yes & 15 & 49.4 & 27.8 \\
& Total & 43 & 56.3 & 24.2 \\
\hline
\end{tabular}

autopsy, only $10.3-33.3 \%$ of patients who died of falls and $0.0-50.0 \%$ of patients who died of penetrating trauma underwent autopsy (Table 2).

Three patients $(4.2 \%)$ died within the first hour (immediate death), and 17 patients (23.9\%) within the first $4 \mathrm{~h}$ after the trauma (early death). Seventeen patients (23.9\%) died within the first 2 days, and 12 patients (16.9\%) died within 7 days after the trauma. Twenty-two patients (31.0\%) died $>7$ days (late death) after the trauma (late death) (Fig. 1).

\section{Clinical cause of death according to death certificate}

On the death certificate, clinicians classified $47.9 \%$ of deaths as caused by sTBI $(n=34), 9.9 \%$ as caused by thoracic trauma $(n=7), 9.9 \%$ as caused by multiple organ failure $(n=7), 8.4 \%$ as caused by multiple trauma $(n=6)$, $2.8 \%$ as caused by respiratory failure $(n=2)$, and $2.8 \%$ as caused by exsanguination $(n=2)$. In 13 cases, the death certificate indicated an unspecific other cause of death $(18.3 \%)$.

The distribution of clinical causes of death as related to the survival time is shown in Table 3.

In seven cases, a multiple organ failure (MOF) was testified as cause of death. The average age of the deceased was 63.7 years, reflecting the older demographic. Since our patient cohort represented the elderly population, we decided to subgroup the subjects according to an age limit of 45 years, which reflects the young, reproductive

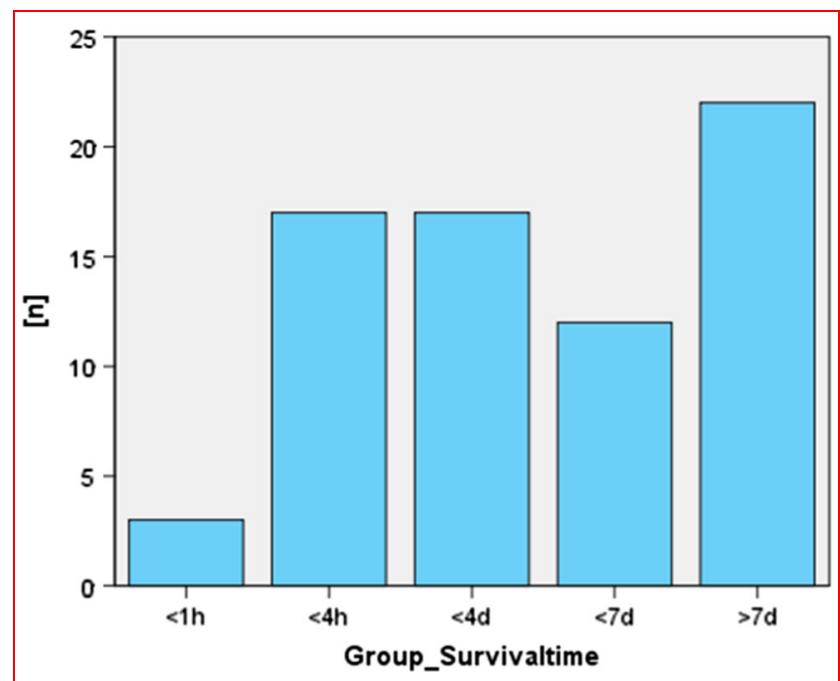

Fig. 1 Survival time. Most of the traumatic deaths occurred within 4 days after the trauma $(n=37)$

population versus the elderly. Table 4 gives an overview about length of hospital stay, ICU admissions and ICU length of stay, respiratory distress, other related complications, and different scores. The classification of the cases took place according to age ( $\leq 45$ years or $>45$ years) as well as carrying or not carrying out an autopsy.

\section{Autopsy findings}

\section{Injury pattern}

Traffic accidents were the most frequent cause of polytrauma $(n=17 ; 68 \%)$, followed by falls from a height $(>3 \mathrm{~m})(n=3 ; 12 \%)$. Traffic accidents involved pedestrians $(n=7)$, cyclists $(n=5)$, and occupants $(n=5)$. Other causes were falls $(<3 \mathrm{~m})$, stab wounds, shaken impact syndrome, and work-related accidents.

An overview of all autopsied cases is shown in Table 5.

\section{Discrepancies in causes of death}

Evident discrepancies with evident clinical consequences were ascertained in $4 \%$ of cases $(1 / 25)$ and those with

Table 2 Interaction of trauma mechanism and mandate for autopsy

\begin{tabular}{lclllccccc}
\hline Autopsy & Other & Falls $>3 \mathrm{~m}$ & Falls $<3 \mathrm{~m}$ & Shotgun & Stab wounds & TA pedestrian & TA cyclist & TA occupant & Total \\
\hline No & 2 & 26 & 4 & 2 & 1 & 0 & 5 & 6 \\
Yes & 2 & 3 & 2 & 0 & 1 & 7 & 5 & 5 \\
Yes $(\%)$ & 50 & 10.3 & 33.3 & 0 & 50 & 100 & 50 & 46.5 \\
Total & 4 & 29 & 6 & 2 & 2 & 7 & 10 & 11 \\
\hline
\end{tabular}

$T A$ traffic accident 
Table 3 Distribution of clinical causes of death in matters of the survival time; $\mathrm{h}=$ hours; $\mathrm{d}=$ days

\begin{tabular}{llccccc}
\hline Cause of death & \multicolumn{6}{l}{ Survival time } \\
\cline { 2 - 7 } & $<1 \mathrm{~h}$ & $1-4 \mathrm{~h}$ & $4-48 \mathrm{~h}$ & $2-7 \mathrm{~d}$ & $>7 \mathrm{~d}$ & Total \\
\hline Others & 0 & 0 & 4 & 4 & 5 & 13 \\
Polytrauma & 1 & 4 & 1 & 0 & 0 & 6 \\
sTBI & 2 & 7 & 13 & 5 & 7 & 34 \\
Exsanguination & 0 & 2 & 0 & 0 & 0 & 2 \\
Thoracic trauma & 0 & 5 & 2 & 0 & 0 & 7 \\
MOF & 0 & 0 & 1 & 1 & 5 & 7 \\
Respiratory failure & 0 & 0 & 0 & 0 & 2 & 2 \\
Total & 3 & 18 & 21 & 10 & 19 & 71 \\
\hline
\end{tabular}

sTBI severe traumatic brain injury, $M O F$ multiple organ failure

marginal clinical consequences ascertained in 24\% (6/25). Marginal discrepancies with minor forensic consequences were ascertained in $16 \%(4 / 25)$ (Table 6).

A detailed report of case 5 (evident discrepancy) involving clinical and forensic discrepancies is presented below.
Case 5 (male, 61 years)

The patient was a passenger involved in a head-on collision with a sport utility vehicle. Upon arrival to the pre-hospital emergency physician (specialized doctor of the pre-hospital ambulance team in the German Rescue System), the patient was awake and seated in the car. No verbal communication was possible because of a preexisting tracheostomy caused by laryngeal carcinoma. Due to thoracic instability with respiratory distress, the patient was ventilated and anesthetized (Ketamine, Midazolam). During transportation via a rescue helicopter, the patient's vital signs deteriorated with electrocardiographic signs of a myocardial infarction. On admission in emergency room (+79 min), CPR was in progress [base excess (BE), $-15 \mathrm{mmol} / \mathrm{L}$; ISS, 34; NISS, 50; RISC II, survival 1\%]. A physical examination confirmed an unstable chest with breathing sounds on both sides. A chest tube was inserted on the left side. Arterial and venous access was established, and an intraosseous cannula was inserted into the proximal tibia (retrospectively no information on the administered infusion available). Focused assessment with sonography in trauma (FAST) results was negative with no free abdominal fluid, no hemopericardium, and no signs of left heart insufficiency on transthoracic echocardiography. Death was certified 110 min after trauma $(31$ min. after

Table 4 Presentation of the autopsied and non-autopsied patients separated by age ( $\leq 45$ years and $>45$ years), length of stay in hospital, ICU admissions and length of stay, respiratory distress, other related complications, and different scores

\begin{tabular}{|c|c|c|c|c|}
\hline & \multicolumn{2}{|l|}{ Age $\leq 45$ years } & \multicolumn{2}{|l|}{ Age $>45$ years } \\
\hline & No autopsy & Autopsy & No autopsy & Autopsy \\
\hline Patients [n] & 7 & 7 & 39 & 18 \\
\hline Days in hospital [mean (min; max)] & $11(1 ; 55)$ & $2.4(1 ; 5)$ & $8.5(0 ; 39)$ & $7.9(1 ; 56)$ \\
\hline Days on ICU [mean (min; max)] & $11(0 ; 55)$ & $2.1(0 ; 5)$ & $8.2(0 ; 39)$ & $7.1(0 ; 54)$ \\
\hline SIRS* $^{*}[\mathrm{n}]$ & $5(71 \%)$ & $5(71 \%)$ & $33(85 \%)$ & $13(72 \%)$ \\
\hline SOFA-Score Changing** & $5(71 \%)$ & $5(71 \%)$ & $31(79 \%)$ & $11(61 \%)$ \\
\hline SOFA highest Score during treatment [mean (min; $\max )]$ & $14(11 ; 19)$ & $15(12 ; 20)$ & $15.23(8 ; 22)$ & $15.5(11 ; 22)$ \\
\hline SAPS II highest Score during treatment [mean (min; max)] & $65(53 ; 83)$ & $67.8(44 ; 82)$ & $\begin{array}{l}80.72(54 \\
110)\end{array}$ & $78.8(61 ; 101)$ \\
\hline APACHE II highest Score during treatment [mean (min; max)] & $35.4(31 ; 39)$ & $33.2(26 ; 40)$ & $36.38(26 ; 54)$ & $38.9(29 ; 50)$ \\
\hline $\begin{array}{l}\mathrm{PaO}_{2} / \mathrm{FiO}_{2} \text { by PEEP }>5 \mathrm{cmH}_{2} \mathrm{O},<300 \mathrm{mmHg} \text { or SOFA-Ventilation } 2 / 3 / \\
\quad 4[\mathrm{n}]\end{array}$ & $5(71 \%)$ & $5(71 \%)$ & $30(77 \%)$ & $11(61 \%)$ \\
\hline Lactate $(\mathrm{mmol} / \mathrm{l})$ by arriving emergency room [mean (min; max)] & $7.02(2.0 ; 17.0)$ & $6.3(2.7 ; 10.4)$ & $\begin{array}{l}3.69(0.6 \\
11.0)\end{array}$ & $\begin{array}{l}3.95(0.4 ; \\
17.0)\end{array}$ \\
\hline highest Lactate $(\mathrm{mmol} / \mathrm{l})[$ mean $(\mathrm{min} ; \mathrm{max})]$ & $\begin{array}{l}11.34(4.9 ; \\
26.0)\end{array}$ & $\begin{array}{l}8.53(4.2 \\
17.0)\end{array}$ & $\begin{array}{l}8.08(0.6 \\
31.0)\end{array}$ & $\begin{array}{l}8.66(1.6 \\
28.0)\end{array}$ \\
\hline
\end{tabular}

A significant difference was seen through the variables due to age group $</>45$, gender ( $p$ 0.006), SAPS II highest score during treatment ( $p$ 0.004), and lactate upon arrival in the emergency room $(p 0.015)$

*Diagnosis of SIRS-minimal 2 criteria: $>38{ }^{\circ} \mathrm{C}$ or $<36{ }^{\circ} \mathrm{C}$; heart frequency $>90 / \mathrm{min}$; ventilation $>19 / \mathrm{min}_{\text {or }} \mathrm{pCO} \mathrm{CO}_{2}<32 \mathrm{mmHg}$; leukocytes $>12.000 / \mu 1$ or $<4.000 / \mu 1$

$* *$ SOFA-score changes $>2$ points per day and lactate $>2 \mathrm{mmol} / \mathrm{l}$ 


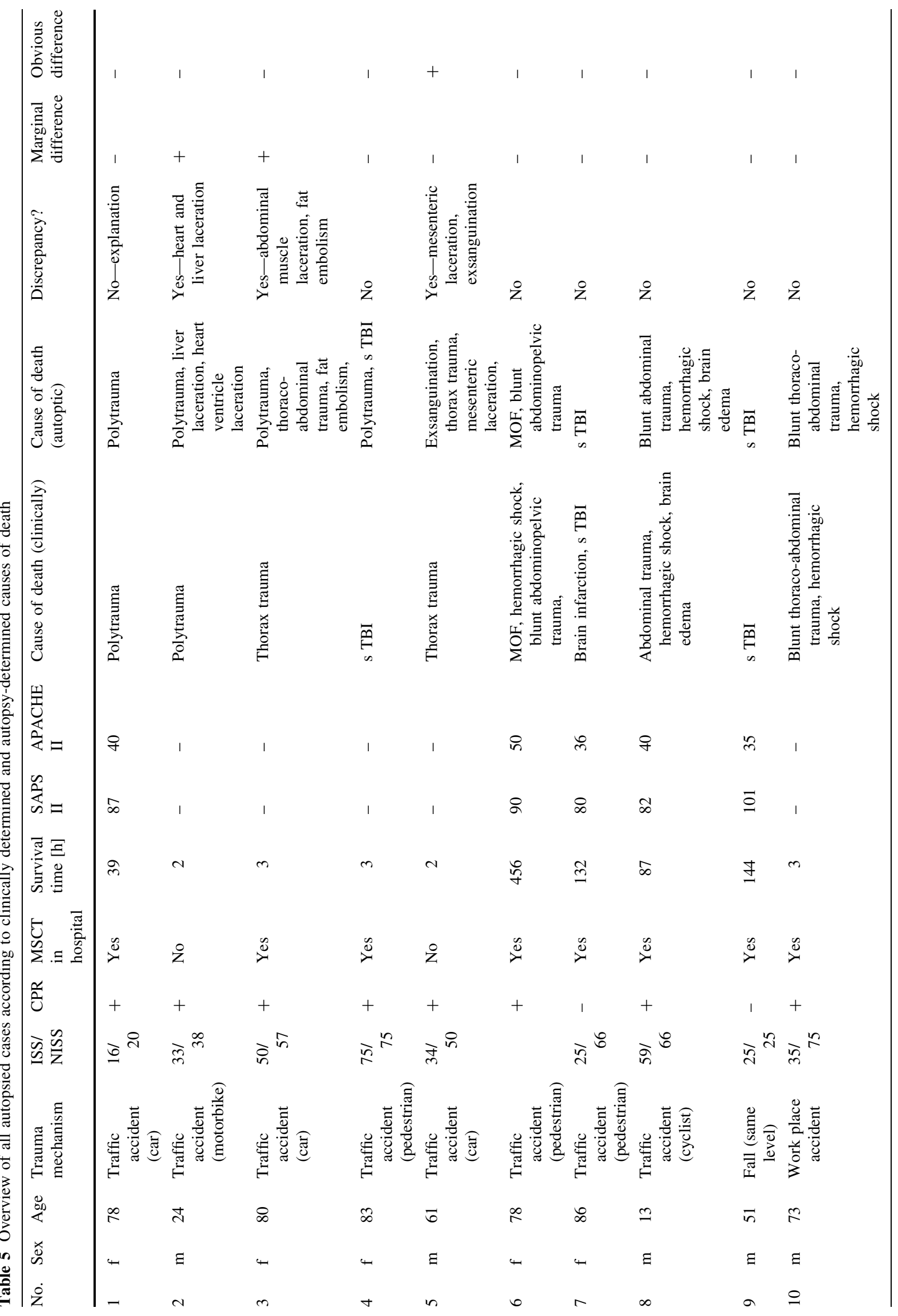




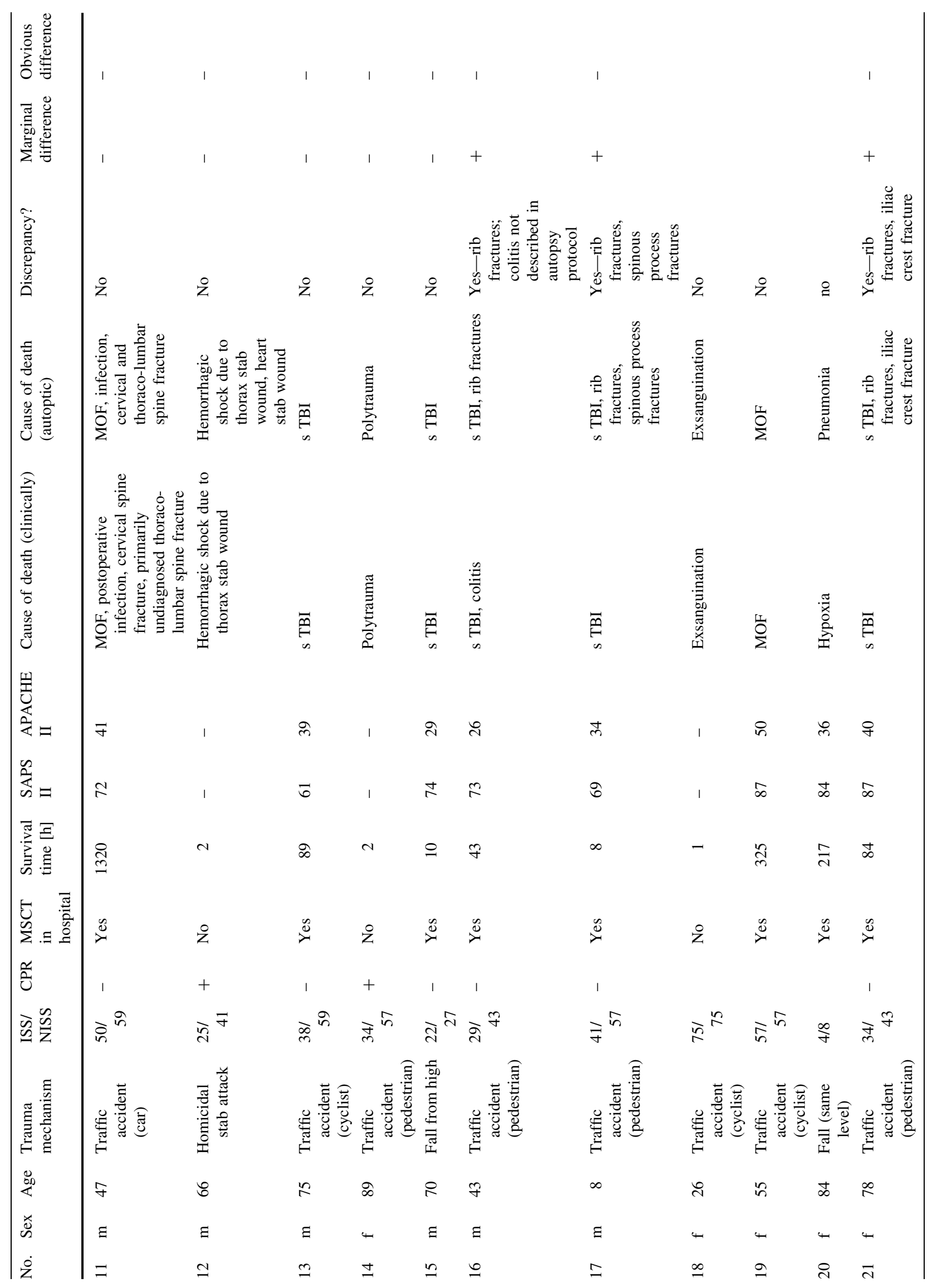




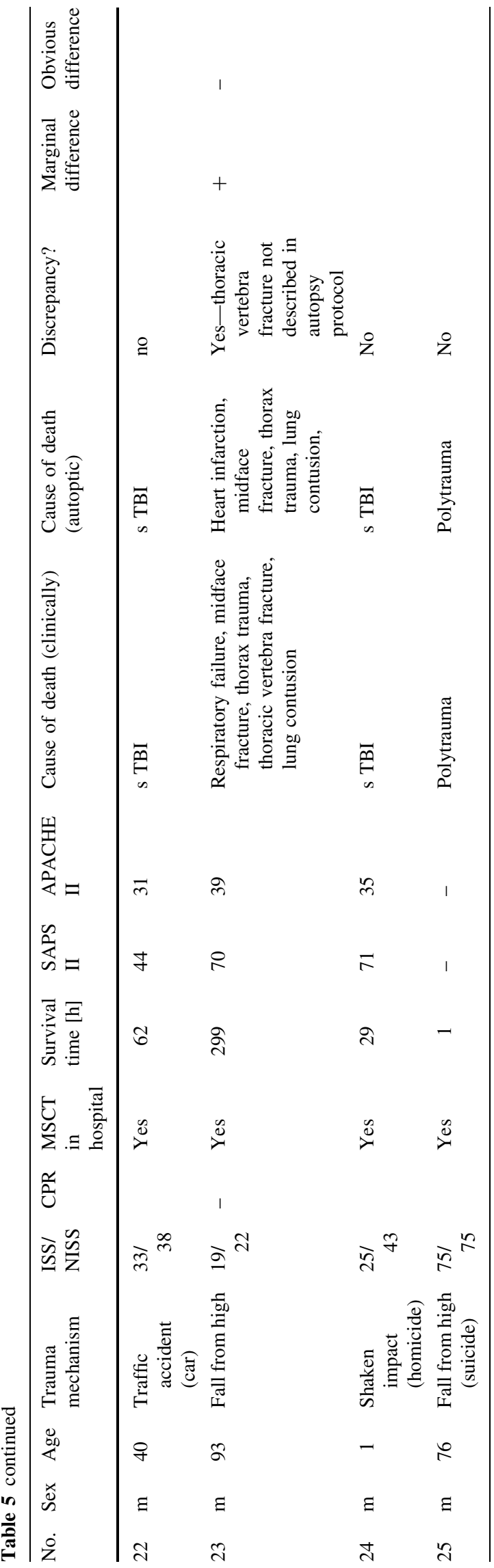

admission in the ER), and the cause of death was determined to be thoracic trauma with cardiac contusion and cardiac shock.

Autopsy confirmed the clinically described findings of blunt thoracic trauma. Additionally, bilateral hemothorax $(400 \mathrm{ml})$ with intrapulmonary malposition of the left chest tube was revealed. Furthermore, several mesenteric lacerations leading to $1000 \mathrm{ml}$ of hemoperitoneum were diagnosed.

The immediate cause of death was exsanguination. During trauma management, the predominant bleeding source in the abdomen was not diagnosed. Furthermore, cardiopulmonary resuscitation (CPR) in patients with trauma should include bilateral chest decompression, which was not performed. These findings are allocated to evident discrepancy with clinical consequences, i.e., emergency laparotomy and bilateral chest decompression. The heart showed signs of both chronic vascular disease and new infarction.

At the time of autopsy, the forensic pathologist was informed that the injured person had passed away at the accident site. This misinformation led to an incorrect description of the place of death in the autopsy report. This issue was evaluated as a marginal discrepancy.

\section{Discussion}

Primary management of patients with polytrauma poses high demands of EPs and clinicians. Missed diagnosis during initial assessment and diagnostic workup is a hard reality in a small yet significant number of trauma patients [11]. Trauma management has improved due to innovations such as standing MSCT [10]. However, the widespread use of high-technology MSCT means that clinicians are not accustomed to diagnosing life-threatening injuries by clinical investigation, standard X-ray examination, or FAST examination. In patients with complex injury pattern with instability or in severely injured patients, physicians must make decisions in difficult circumstances (e.g., ongoing CPR), limiting the standard use of diagnostic techniques such as $\mathrm{CT}$ and $\mathrm{X}$-ray examination.

Therefore, we performed a retrospective study of 517 patients with trauma (71 trauma-related deaths) at a level I trauma center. The average age of the deceased was 63.7 years, which is uniquely higher than that in other studies, reflecting the older demographic $[6,17]$.

In $93 \%$ of patients, blunt trauma was the cause of death. The predominant mechanisms of trauma were falls (49\%) and traffic accidents (39\%), reflecting the rural catchment area of our trauma center in east Saxony. The leading clinical cause of death was sTBI $(n=34 ; 48.0 \%)$, followed by thoracic trauma $(n=7 ; 10.0 \%)$, multiple organ failure 
Table 6 Discrepancies of clinical and forensic death causes and diagnosis: six marginal and one evident discrepancies on the clinician and four marginal discrepancies on the coroner side

\begin{tabular}{|c|c|c|c|c|c|}
\hline No & $\begin{array}{l}\text { Survival time } \\
\text { [hh:min] or } \\
\text { [days] }\end{array}$ & $\begin{array}{l}\text { MSCT } \\
\text { in } \\
\text { hospital }\end{array}$ & Autopsy death cause & Discrepancy Fault clinician & Discrepancy Fault coroner \\
\hline 2 & 01:08 & no & $\begin{array}{l}\text { Polytrauma sTBI } \\
\text { combined with } \\
\text { hemorrhagic shock }\end{array}$ & $\begin{array}{l}\text { Marginal missed vascular injury, heart rupture and liver } \\
\text { injury }\end{array}$ & \\
\hline 3 & $02: 30$ & yes & $\begin{array}{l}\text { Polytrauma } \\
\text { hemorrhagic shock, } \\
\text { fat embolism }\end{array}$ & $\begin{array}{l}\text { Marginal misinterpretation of abdominal soft tissue } \\
\text { trauma to hernia }\end{array}$ & $\begin{array}{l}\text { Marginal missed lumbar } \\
\text { fracture and proc. } \\
\text { transverse fractures }\end{array}$ \\
\hline 5 & $01: 50$ & no & Exsanguination & $\begin{array}{l}\text { Evident missed multiple mesenteric laceration with } \\
1000 \mathrm{ml} \text { hemoperitoneum, pneumothorax right and } \\
\text { intrapulmonary chest drain left }\end{array}$ & $\begin{array}{l}\text { Marginal wrong place of } \\
\text { death in autopsy record }\end{array}$ \\
\hline 16 & 2 days & yes & sTBI & Marginal missed rib fractures & $\begin{array}{l}\text { Marginal colitis (CT } \\
\text { report) not mention in } \\
\text { autopsy }\end{array}$ \\
\hline 17 & 07:06 & yes & sTBI & $\begin{array}{l}\text { Marginal missed spleen contusion, rib fractures and Proc. } \\
\text { spine fractures }\end{array}$ & \\
\hline 21 & 3 days & yes & sTBI & Marginal missed pelvic rim and rib fractures & \\
\hline 23 & 13 days & yes & Myocardial infarction & Marginal not natural death cause & $\begin{array}{l}\text { Marginal missed thoracic } \\
\text { spine fracture }\end{array}$ \\
\hline
\end{tabular}

MSCT multislice computed tomography

( $n=7 ; 10.0 \%)$, polytrauma $(n=6 ; 8.4 \%)$, exsanguination $(n=2 ; 2.8 \%)$, and respiratory failure $(n=2 ; 2.8 \%)$.

In two cases, a respiratory failure was diagnosed by the clinicians. In the first case, the cause was due to pemphigoid with tracheal stenosis (autopsy cause of death pneumonia). In the second case, a lung contusion by fall from height was the assumed cause of death (autopsy cause of death myocardial infarction).

These distributions of the trauma mechanisms and causes of death are comparable with those in other studies $[7,9]$.

The mortality rate in the observation period was $13.7 \%$ with a calculated probability of survival via the RISC II score of $17.9 \%$ [16]. Despite the high trauma-related mortality rate at our center $(11.2 \%$ mortality rate in the German Trauma Registry 2017), trauma management delivers a survival advantage of $4.2 \%$. Therefore, patients at our center have more severe trauma than the German general population.

In accordance with Trunkey's trimodal model, we detected peaks of traumatic deaths, within $<4 \mathrm{~h}$, within $4 \mathrm{~h}$ and $<4 \mathrm{~d}$, and after $>7$ days. Kleber et al. [6] observed the absence of the third peak (late death), which has not yet been confirmed in this study.

The value of autopsy to the quality assurance of traumarelated death is controversial [1, 5, 6, 18-22]. In the present study, ten marginal and one evident clinical discrepancies and four marginal forensic discrepancies occurred among seven cases. These discrepancies were found in the clinical records $(n=7)$ and in the autopsy protocols $(n=4)$. This confirms previous reports that a significant number of injuries are missed antemortem and that the autopsy is of value in diagnosing missed injuries [17].

The one case of evident discrepancy with potential clinical impact was an intestinal laceration with severe abdominal bleeding ( $1 \mathrm{~L}$ of hemoperitoneum) in a patient with blunt abdominal trauma. At the emergency department, the FAST examination result was false-negative. Because of the known low sensitivity of FAST examination, the false-negative result was taken as fixed; therefore, no intervention or emergency laparotomy was performed. In contrast, the autopsy revealed this injury to be the main bleeding source that contributed to exsanguination. In the peer-review process, the death was determined to be unpreventable.

In lethal polytrauma, the clinically accepted causes of death can deviate from those determined by autopsy. This disparity is influenced by various factors including preexisting disease, age, the trauma mechanism, the performance of CPR, the survival time, and the possibility of performing MSCT or emergency diagnostics. If a serious injury pattern with an elevated ISS ( $>25$ points) necessitates continuous resuscitative efforts, further diagnostic measures are required in addition to the physical investigations, and thoracic and pelvic X-rays are necessary for diagnostic safety and clinical management. For unstable or severely injured patients, the performance of MSCT is often impossible. Such patients in the present study died before 
specific and secure diagnostics were performed. The cause of death on the clinical death certificate relies on the physician's clinical experience or the physical examination findings. Particularly in patients with blunt trauma, the physical examination ("body check") is often unreliable with regard to internal injury patterns ("Casper's sign") [23]. These deaths are classified as immediate or early deaths. However, complications (e.g., coagulopathy, acute respiratory distress syndrome, or lung embolism) in late deaths lead to diagnostic uncertainties and misjudgment of the clinical course.

Autopsy can provide valuable support by clarifying important clinical and forensic questions:

- Definitive cause of death

- Forensic manner of death

- Comparison of clinical examination findings and diagnoses (quality assurance) with autopsy findings

- Determination of causality between trauma and occurrence of death

These points are highlighted in Case 23 of the present study. The global respiratory failure was clinically interpreted as a result of lung contusions. Therefore, the clinicians reported that the death was not from natural causes. However, autopsy revealed a cardiac infarction as the underlying cause of the respiratory failure, and the forensic pathologist thus classified the manner of death as natural.

The causes of death after clinical and autopsy investigations showed fair correspondence $(72 \% ; 18 / 25)$ in our study; however, potential for improvement existed in seven cases $(28 \%)$. In accordance with Steinwall et al., it is pertinent to note that the low incidence of clinically relevant missed injuries reflects well on the clinical trauma service and radiological departments [17].

From a forensic viewpoint, the high proportion of patients with trauma-related deaths who did not undergo autopsy is alarming (Table 2). Autopsies can be undertaken only with appropriate consent or other authorization, which defines the limits of the procedure [24]. The public prosecutor requested autopsies in most cases of traffic accidents ( $100 \%$ of cases involving pedestrians); however, autopsies were not requested for patients who died of other trauma mechanisms (falls, 14\%; shotgun injuries, $0 \%$ ). According to German law, physicians must report every non-natural or even unclear classified death to the police. The public prosecutor then decides based on the records whether an autopsy is required.

The public prosecutor orders autopsies only in suspicious cases or those with unlawful backgrounds. The costs are carried out by the prosecutor. Autopsies will not be financed by the prosecutor for clinical investigations or improving quality of management purposes. Therefore, only a small percent of deceased trauma patients will receive an autopsy. A shift in these fundamental rules will not be changed in Germany in the foreseeable future.

Patients who died and underwent subsequent autopsy were significantly younger than those without autopsy. Because this was a retrospective study, it was not possible to determine the reasons for not performing autopsies. But this is not just a national problem in Germany. The autopsy frequency of blunt and penetrating trauma deaths in the USA increased by $14.3 \%$ during the 1980 s to $58.9 \%$ in 1989 , while the autopsy frequency of all deaths decreased by $23.6 \%$ during the same period to $11.5 \%$ in 1989 . Among trauma deaths, homicides remained far more likely to be autopsied than non-homicides. The autopsy frequency of homicidal trauma deaths in 1989 was $90.0 \%$ or higher in 44 states. The autopsy frequency of non-homicidal trauma deaths in 1989 ranged from $10.3 \%$ in Oklahoma to $94.5 \%$ in Hawaii [25]. Beck et al. [26] described in a study about potentially preventable trauma deaths that $42.9 \%$ of all cases underwent a full autopsy.

For us, the autopsy is the gold standard method to determine the cause of death and ensure quality management in trauma-related deaths. Autopsy is valuable as the last medical procedure performed for quality assurance of treatment. It is performed to examine the medical measures taken and provide important feedback to clinicians [12]. Autopsy results can simultaneously be used to support police investigations. Without autopsy, there is a real danger that external factors responsible for the death are not recognized.

However, autopsy also has limitations. Only with comprehensive knowledge of all clinical findings can these findings be confirmed in the autopsy report. The fact that fractures were not described as findings in two autopsy reports underlines the importance of postmortem MSCT $[27,28]$.

In different studies, the clinical evidence of the postmortem computed tomography (PMCT) was compared with autopsy results. Although the accuracy of the PMCT is impressive, it still does not replace the exactness and correctness of the autopsy. A combination of both methods is apparently the right strategy to achieve the best findings [29-31].

In summary, the autopsy remains an important tool in evaluating trauma care [17].

Because trauma accounts for the greatest loss of human life, preventive aspects (e.g., car and truck safety systems) must not be neglected with regard to prospective safeguarding of human life. Particularly in cases of fatal trauma, interdisciplinary collaboration of forensic medicine and trauma surgery has high educational potential and significant scientific innovation potential with retrospective evaluation of hospital and pre-hospital trauma care. Such collaboration aids forensic scientists in understanding 
emergency medicine at autopsy and encourages clinical physicians to question existing guidelines based on autopsy findings. We can learn a lot from each other [32]. A good way could be regular trauma mortality meetings. In special cases, the pathologist can personally advise the clinician by being present for the autopsy. This feedback could encourage its clinical colleagues to mandate a clinical autopsy with the allowance of the family members.

For these reasons, we recommend a high autopsy rate and close cooperation between the fields of traumatology and forensic medicine with interdisciplinary conferences to secure or improve the quality of clinical management and autopsy reports. We call for standardized evaluation of traumatic deaths via autopsy and postmortem MSCT. Buschmann et al. [1] proposed the inclusion of autopsy data from such polytrauma fatalities in national trauma registries, so further research projects on this topic could be considered. Unfortunately, it has not yet been carried out.

\section{Limitations}

This was a retrospective single-center study performed at a level I trauma center with a small group of patients. Comparison of our results with those from other hospitals, particularly those not specialized in trauma, is not possible without limitations.

We consider the results to be reliable because the examination of the clinical records, death certificates, and final postmortem reports allowed detailed postprocessing of every traumatic death in our study due to the close, personal interaction between the surgical and forensic experts.

Another limitation of our study is the fact that the public prosecutor decided whether a forensic autopsy was performed. Therefore, this was not a medical but a forensic decision. Unlike in other countries, a forensic autopsy is not performed for all trauma-related deaths in Germany. It can therefore be assumed that there is considerable ambiguity in the correctness of clinical diagnoses because of this public prosecutorial "bias." The medicolegal autopsy rate remains stable at a low level of about $2 \%$. This rate is alarmingly low compared with other European countries [33].

\section{Conclusions}

In most cases, blunt trauma was the cause of death. The predominant trauma mechanisms were falls and traffic accidents, reflecting the rural catchment area of our trauma center. The circumstances of trauma and the age of the victim are important factors in the public prosecutor's decision regarding whether to request an autopsy. Men who underwent autopsy were significantly younger than men without autopsy. A high autopsy rate provides a chance to not only reveal missed injuries and understand the pathomechanism in each trauma fatality but also to discover potential diagnostic insufficiencies in the clinical course and the forensic autopsy. Our systematic care review discovered some discrepancies between the clinically and the forensically determined cause of death and also revealed some missed injuries on both sides. Interdisciplinary cooperation between trauma surgeons and forensic pathologists can increase the quality of trauma management.

Acknowledgement Open Access funding provided by Projekt DEAL. We thank Angela Morben, DVM, ELS, from Edanz Group (www.edanzediting.com/ac), and Kate Nowotnick (native speaker) for editing a draft of this manuscript.

\section{Compliance with ethical standards}

Conflict of interest The authors declare that they have no conflict of interest.

Open Access This article is licensed under a Creative Commons Attribution 4.0 International License, which permits use, sharing, adaptation, distribution and reproduction in any medium or format, as long as you give appropriate credit to the original author(s) and the source, provide a link to the Creative Commons licence, and indicate if changes were made. The images or other third party material in this article are included in the article's Creative Commons licence, unless indicated otherwise in a credit line to the material. If material is not included in the article's Creative Commons licence and your intended use is not permitted by statutory regulation or exceeds the permitted use, you will need to obtain permission directly from the copyright holder. To view a copy of this licence, visit http://creativecommons. org/licenses/by/4.0/.

\section{References}

1. Buschmann CT, Gahr P, Tsokos M et al (2010) Clinical diagnosis versus autopsy findings in polytrauma fatalities. Scand J Trauma Resusc Emerg Med 18:1-9. https://doi.org/10.1186/1757-7241$18-55$

2. Lovrić Z (2015) Definition of polytrauma: discussion on the objective definition based on quantitative estimation of multiply injured patients during wartime. Injury 46:S24-S26. https://doi. org/10.1016/j.injury.2015.10.048

3. Paffrath T, Lefering R, Flohé S (2014) How to define severely injured patients? An Injury Severity Score (ISS) based approach alone is not sufficient. Injury 45:S64-S69. https://doi.org/10. 1016/j.injury.2014.08.020

4. Tien H, Chu PTY, Brenneman F (2004) Causes of death following multiple trauma. Curr Orthop 18:304-310. https://doi.org/ 10.1016/j.cuor.2004.04.006

5. David JS, Bouzat P, Raux M (2018) Evolution and organisation of trauma systems. Anaesth Crit Care Pain Med. https://doi.org/ 10.1016/j.accpm.2018.01.006 
6. Kleber C, Giesecke MT, Tsokos M et al (2012) Overall distribution of trauma-related deaths in Berlin 2010: advancement or stagnation of German trauma management? World J Surg 36:2125-2130. https://doi.org/10.1007/s00268-012-1650-9

7. Pfeifer R, Tarkin IS, Rocos B, Pape HC (2009) Patterns of mortality and causes of death in polytrauma patients-has anything changed? Injury 40:907-911. https://doi.org/10.1016/j. injury.2009.05.006

8. Trunkey DD (1983) Trauma. Accidental and intentional injuries account for more years of life lost. Sci Am 249:28-35

9. Probst C, Pape HC, Hildebrand F et al (2009) 30 years of polytrauma care: an analysis of the change in strategies and results of 4849 cases treated at a single institution. Injury 40:77-83. https:// doi.org/10.1016/j.injury.2008.10.004

10. Huber-Wagner S, Lefering R, Qvick LM et al (2009) Effect of whole-body CT during trauma resuscitation on survival: a retrospective, multicentre study. Lancet 373:1455-1461. https://doi. org/10.1016/S0140-6736(09)60232-4

11. Sharma BR, Gupta M, Harish D, Singh VP (2005) Missed diagnoses in trauma patients vis-a-vis significance of autopsy. Injury 36:976-983

12. Kleber C, Giesecke MT, Tsokos M et al (2013) Trauma-related preventable deaths in Berlin 2010: need to change prehospital management strategies and trauma management education. World J Surg 37:1154-1161. https://doi.org/10.1007/s00268-0131964-2

13. Dickmann P, Bauer M (2019) Sepsis 2019-new trends and their implications for multiple trauma patients. Z Orthop Unfall. https://doi.org/10.1055/a-0853-2054

14. Singer M, Deutschman CS, Seymour CW et al (2016) The third international consensus definitions for sepsis and septic shock (Sepsis-3). JAMA 315:801-810. https://doi.org/10.1001/jama. 2016.0287.The

15. Lopes Ferreira F, Peres Bota D, Bross A et al (2001) Serial evaluation of the SOFA score to predict outcome. JAMA. https:// doi.org/10.1001/jama.286.14.1754

16. Lefering R, Huber-Wagner S, Nienaber U et al (2014) Update of the trauma risk adjustment model of the TraumaRegister $\mathrm{DGU}^{\mathrm{TM}}$ : the Revised Injury Severity Classification, version II. Crit Care 18:1-12. https://doi.org/10.1186/s13054-014-0476-2

17. Steinwall D, Befrits F, Naidoo SR et al (2012) Deaths at a Level 1 trauma unit: a clinical finding and post-mortem correlation study. Injury 43:91-95. https://doi.org/10.1016/j.injury.2010.11.004

18. Martin BT, Fallon WF, Palmieri PA et al (2007) Autopsy data in the peer review process improves outcomes analysis. J Trauma Inj Infect Crit Care 62:69-73. https://doi.org/10.1097/TA. 0b013e31802d08e5

19. Ong AW, Cohn SM (2007) Comment on "Autopsy data in the peer review process improves outcomes analysis". J Trauma Inj Infect Crit Care 62:1541. https://doi.org/10.1097/TA. 0b013e3180592ae8

20. Scantling D, Teichman A, Kucejko R et al (2017) Identifying preventable trauma death: does autopsy serve a role in the peer review process? J Surg Res 215:140-145. https://doi.org/10.1016/ j.jss.2017.03.068
21. O'Connor AE, Parry JT, Richardson DB et al (2002) A comparison of the antemortem clinical diagnosis and autopsy findings for patients who die in the emergency department. Acad Emerg Med 9:957-959

22. Tavora F, Crowder CD, Sun CC, Burke AP (2008) Discrepancies between clinical and autopsy diagnoses: a comparison of university, community, and private autopsy practices. Am J Clin Pathol 129:102-109. https://doi.org/10.1309/ 9M7DFE62RTDKHH4D

23. Byard RB (2012) How reliable is external examination in identifying internal injuries - Casper's sign revisited. J Forensic Leg Med 19:419-421. https://doi.org/10.1016/j.jflm.2012.02.00

24. Burton JL, Underwood J (2007) Clinical, educational, and epidemiological value of autopsy. Lancet 369:1471-1480. https:// doi.org/10.1016/S0140-6736(07)60376-6

25. Pollock DA, O'neil JM, Parrish RG et al (1993) Temporal and geographic trends in the autopsy frequency of blunt and penetrating trauma deaths in the united states. JAMA J Am Med Assoc 269:1525-1531. https://doi.org/10.1001/jama.1993. 03500120063027

26. Beck B, Smith K, Mercier E et al (2019) Potentially preventable trauma deaths: a retrospective review. Injury 50:1009-1016. https://doi.org/10.1016/j.injury.2019.03.003

27. Jalalzadeh H, Giannakopoulos GF, Berger FH et al (2015) Postmortem imaging compared with autopsy in trauma victims-a systematic review. Forensic Sci Int 257:29-48. https://doi.org/10. 1016/j.forsciint.2015.07.026

28. Moskała A, Woźniak K, Kluza P et al (2016) The importance of post-mortem computed tomography (PMCT) in confrontation with conventional forensic autopsy of victims of motorcycle accidents. Leg Med 18:25-30. https://doi.org/10.1016/j.legalmed. 2015.11.005

29. Ampanozi G, Thali YA, Schweitzer W et al (2017) Accuracy of non-contrast PMCT for determining cause of death. Forensic Sci Med Pathol 13:284-292. https://doi.org/10.1007/s12024-0179878-1

30. Kirchhoff SM, Scaparra EF, Grimm J et al (2016) Postmortem computed tomography (PMCT) and autopsy in deadly gunshot wounds-a comparative study. Int J Legal Med 130:819-826. https://doi.org/10.1007/s00414-015-1225-Z

31. Scaparra E, Peschel O, Kirchhoff C et al (2016) Detection of blood aspiration in deadly head gunshots comparing postmortem computed tomography (PMCT) and autopsy. Eur J Med Res 21:1-8. https://doi.org/10.1186/s40001-016-0237-6

32. Buschmann CT, Tsokos M, Kleber C (2015) Preventive pathology: the interface of forensic medicine and trauma surgery for pre-hospital trauma management. Forensic Sci Med Pathol 11:317-318. https://doi.org/10.1007/s12024-014-9603-2

33. Brinkmann B, Du Chesne A, Vennemann B (2002) Aktuelle Daten zur Obduktionsfrequenz in Deutschland. Dtsch Medizinische Wochenschrift 127:791-795. https://doi.org/10.1055/s2002-25021

Publisher's Note Springer Nature remains neutral with regard to jurisdictional claims in published maps and institutional affiliations. 